\title{
ROS production, intracellular HSP70 levels and their relationship in human neutrophils: effects of age
}

\author{
Elena I. Kovalenko${ }^{1}$, Anna A. Boyko ${ }^{1}$, Victor F. Semenkov ${ }^{2}$, Gennady V. Lutsenko ${ }^{1}$, \\ Maria V. Grechikhina ${ }^{1}$, Leonid M. Kanevskiy ${ }^{1}$, Tatyana L. Azhikina ${ }^{1}$, William G. \\ Telford $^{3}$ and Alexander M. Sapozhnikov ${ }^{1}$ \\ ${ }^{1}$ Shemyakin and Ovchinnikov Institute of Bioorganic Chemistry RAS, Moscow, Russia \\ ${ }^{2}$ Centre of Gerontology of Russian State Medical University, Moscow, Russia \\ ${ }^{3}$ National Cancer Institute, National Institute of Health, Bethesda, USA \\ Correspondence to: Elena I. Kovalenko, email: kovalenelen@gmail.com
}

Keywords: Aging, neutrophils, reactive oxygen species, heat shock proteins, HSP70, cell stress

Received: October 21, 2014 Accepted: December 02, 2014Ｐublished: December 03, 2014

This is an open-access article distributed under the terms of the Creative Commons Attribution License, which permits unrestricted use, distribution, and reproduction in any medium, provided the original author and source are credited.

\section{ABSTRACT}

ROS production and intracellular HSP70 levels were measured in human neutrophils for three age groups: young (20-59 years), elders (60-89 years) and nonagenarians (90 years and older). Elders showed higher levels of spontaneous intracellular ROS content compared with young and nonagenarian groups, which had similar intracellular ROS levels. Zymosan-induced (non-spontaneous) extracellular ROS levels were also similar for young and nonagenarians but were lower in elders. However, spontaneous extracellular ROS production increased continuously with age. Correlation analysis revealed positive relationships between HSP70 levels and zymosan-stimulated ROS production in the elder group. This was consistent with a promoting role for HSP70 in ROS-associated neutrophils response to pathogens. No positive correlation between ROS production and intracellular HSP70 levels was found for groups of young people and nonagenarians. In contrast, significant negative correlations of some ROS and HSP70 characteriscics were found for neutrophils from young people and nonagenarians. The observed difference in ROS and HSP70 correlations in elders and nonagenarians might be associated with an increased risk of mortality in older individuals less than 90 years old.

\section{INTRODUCTION}

Aging is usually described as a complex multifactor biological process involving various molecular and functional alterations. Excessive generation of free radicals, especially reactive oxygen species (ROS), together with impaired resistance to cell stress was proposed to play a general role in acceleration of the aging process [1-3]. According to another view, excessive ROS production as well as molecular damage accumulation may accompany aging but does not drive it. Activation of cellular growth and metabolic signaling pathways in mature organisms can lead to aging development and life shortening [4].

Alterations in immune system functioning may also play an important role in human aging. Aged persons are often characterized by a state of chronic inflammation, termed "inflamm-aging" [5]. One feature of this phenomenon is persistent low-grade activation of immune cells, particularly neutrophils that constitute the largest fraction of leukocytes in human organism. Despite a short lifespan these cells play an important role in antibacterial defense. They rapidly migrate to the site of infection, destroy pathogens and initiate inflammatory responses by means of phagocytosis of the pathogens, ROS generation in membrane NADPH oxidase complex, release of cytosolic granules containing proteolytic enzymes, and cytokine/chemokine production. One of the reasons for chronic inflammation may be connected with prolongation of lifespan of activated neutrophils in damaged tissues [6]. It is also known that neutrophil dysfunction is involved in the pathogenesis of many diseases, some of which are associated with age $[7,8]$.

Numerous findings have shown that neutrophils 
are affected by aging and may contribute to immunosenescence. Many functions of neutrophils have been shown to be compromised in the elderly. Chemotaxis, phagocytosis, intracellular killing and NET formation all decline with age [9-11]. Spontaneous neutrophil apoptosis is unchanged or slightly increased and cytokinemediated delay of neutrophil apoptosis is disturbed in aged subjects [12]. Impaired anti-oxidant mechanisms or signal transduction alterations in neutrophils of the elderly people may contribute to the shorter lifespan of these cells $[13,14]$. However, the presence of longlived neutrophils in elderly donors was demonstrated recently [15]. Most findings have demonstrated that ROS production in response to stimulus declines in the elderly [16]. At the same time, spontaneous ROS production of neutrophils may increase with age, participating in chronic inflammatory processes more common in aged persons $[17,18]$.

One mechanism of cell protection from the adverse consequences of ROS action is provided by highly conserved heat shock proteins (HSPs), ubiquitously expressed intracellular stress proteins [19, 20]. These molecular chaperons are involved in correct protein folding and utilization and prevent protein aggregation, providing cell resistance to stress [21]. The HSP70 family consists of several highly homologous proteins, including constitutively expressed Hsc70 and inducible Hsp70. The highly regulated intracellular localization of HSP70 family members plays an essential role in normal cell functions and in protection of cells from unfavorable conditions [22]. Under certain conditions intracellular HSP70 proteins can be translocated to the plasma membrane or be released from the cells forming extracellular pool of these proteins circulating in the body.

Stress resistance is often associated with extension of lifespan. It has been suggested that the impairment of HSP-dependent mechanisms to maintain protein homeostasis could be a factor contributing to aging [23]. This theory has stimulated a series of studies of agerelated changes of HSP70 expression. Most data show that intracellular and serum HSP70 levels were dependent on age. In particular, basal intracellular HSP70 level in blood mononuclear cells was shown to increase in elderly donors [24]. In contrast, the ability of these cells to express HSP70 in response to stress stimulus together with other types of stress responses declined in old age [25]. Concentration of circulating HSP70 in human serum has also been reported to decrease with aging [26, 27]. In mammals and birds higher intracellular levels of heat shock proteins were found in longer-lived organisms [28]. At the same time, low levels of serum Hsp70 were shown to be associated with longevity in humans [29]. Nevertheless, data concerning intracellular content and stress-induced expression of HSP70 in neutrophils are still inconsistent and incomplete. Moreover, there is almost no information about age-associated changes of
HSP70 intracellular levels in these cells as well as their capacity to release these proteins. It is noteworthy that spontaneous ROS production in neutrophils from aged people correlated with HSP70 blood plasma levels [17].

Thus, neutrophils being a plentiful source of both intracellular and extracellular ROS may play a significant role in organism aging. It is unclear whether HSP70 is involved in controlling the process of ROS generation in neutrophils. In this work we have analyzed production of ROS and HSP70 content in neutrophils as well as the relationships of these parameters in three age groups of human individuals: 20-59 (young), 60-89 (elders) and 90 and more (nonagenarians) years of age. We demonstrated that both spontaneous and zymosan-induced ROS production changed with age. Some ROS parameters in the group of nonagenarians ( 90 year and older) were similar to the parameters registered in the group of young volunteers in contrast to the group of elders. Only HSP70 expression associated with heat treatment of neutrophils was found to be age-dependent. Correlation analysis applied to HSP70 and ROS production parameters has revealed multiple relationships between intracellular HSP70 levels and ROS production in neutrophils for different age groups. The positive correlation found only in the group of elders suggests a role for intracellular HPS70 in maintenance of appropriate ROS responses of neutrophils in this group.

\section{RESULTS}

\section{Spontaneous and induced ROS production in neutrophils from young, old and nonagenarian donors}

We initially analyzed age-dependent alterations of ROS generation in human neutrophils using the cells isolated from donors of three age groups: 20-59 (young), 60-89 (elders) and 90 years and older (nonagenarians). Intensive production of ROS is one of the markers of activated neutrophils. It accompanies phagocytosis and secretory degranulation. On the other hand, even freshly isolated neutrophils without any additional stimuli can produce considerable amounts of ROS reflecting their activation history. We analyzed ROS production induced by opsonized zymosan as a characteristic of functional response of neutrophils to a putative pathogen. Before measuring zymosan-induced activation of neutrophils we estimated their spontaneous ROS production. Two methods were applied for spontaneous ROS production assessment: labeling with the cell permeable fluorescent probe DCFHDA (DCF) for cytometric detection of intracellular ROS, and luminol-amplified chemiluminescence (LAC) as a standard approach to evaluation of extracellular ROS production by phagocytes [30]. LAC was also used to analyze zymosan-induced oxidative burst. 
Levels of spontaneously produced ROS detected by LAC $\left(\operatorname{ROS}_{\text {LAC spont }}\right)$ in neutrophils of elders and nonagenarian donors were significantly higher than the ROS $_{\text {LAC spont }}$ levels in neutrophils of young donors (Figure 1a). Spontaneous intracellular ROS generation measured by DCF $\left(\operatorname{ROS}_{\mathrm{DCF} \text { spont }}\right)$ was also significantly increased in the elder group (Figure 1b). However, $\operatorname{ROS}_{\mathrm{DCF} \text { spont }}$ levels in neutrophils of nonagenarians were similar to the levels in young donors in contradiction with the results obtained for $\operatorname{ROS}_{\text {LAC spont }}$. Correlation analysis showed no significant relationship between spontaneous ROS production detected in neutrophils by DCF and LAC in all age groups indicating that the methods discriminated ROS of different kinds and/or produced from different sources.

We then estimated age-dependent changes in ROS production induced in neutrophils by zymosan ROS $_{\mathrm{LAC}}$ ind $)$. This parameter was calculated for each donor as a ratio of the difference between maximal $\left(\operatorname{ROS}_{\mathrm{LAC} \text { max }}\right)$ and initial levels of ROS production to the initial level $\left[\operatorname{ROS}_{\text {LAC ind }}=\left(\operatorname{ROS}_{\text {LAC max }}-\operatorname{ROS}_{\text {LAC spont }}\right) / \operatorname{ROS}_{\text {LAC spont }}\right]$. It should be mentioned that $\operatorname{ROS}_{\mathrm{LAC} \max }$ levels were reached between 10 and 20 min after zymosan addition, depending on the donor. We did not find a significant difference between $\operatorname{ROS}_{\mathrm{LAC} \text { ind }}$ in nonagenarians and young group. At the same time $\mathrm{ROS}_{\mathrm{LAC} \text { ind }}$ levels in elders were significantly lower than in the young donors (Figure 1c). So, functional response of neutrophils did not decline in the nonagenarians in contrast to the elders.

\section{Intracellular HSP70 levels in different age groups and effect of hyperthermia on HSP70 expression}

Cell stress resistance mediated by HSP70 has been proposed as an important anti-aging factor. HSP70 expression in neutrophils in different age donor groups was therefore measured. To estimate intracellular content of the protein we labeled neutrophils with anti-HSP70 antibody (BRM-22, Sigma), recognizing both constitutive (Hsc70) and inducible (Hsp70) forms of HSP70, stained with secondary fluorochrome-conjugated antibody and analyzed them by flow cytometry. We did not reveal any significant age-dependent alterations in HSP70 content $\left(\mathrm{HSP}_{70} \mathrm{basal}\right)$ in the cells (Figure 2). Nevertheless, the insignificant decrease in $\mathrm{HSP} 70_{\text {basal }}$ median in neutrophils from the older donor groups might indicate that a more significant difference might be detected in a future study with larger sampling.

We then analyzed effect of heat shock, the classic stress-inducing microenvironmental condition, on HSP70 expression in neutrophils from the three age groups. Two models of in vitro cell hyperthermia, $40 \mathrm{~min}$ at $40^{\circ} \mathrm{C}$ and $10 \mathrm{~min}$ at $43^{\circ} \mathrm{C}$, were applied to induce a HSP70 stress response in neutrophils. Changes in intracellular HSP70 levels in response to the hyperthermic stress were then measured using the described above immunolabeling protocol. No significant increase in intracellular levels of HSP70 was observed during $4.5 \mathrm{~h}$ after heat treatment except a brief increase in HSP70 level immediately after treatment in the cell samples subjected to $43^{\circ} \mathrm{C}$ heating (Figure 3a). However, mRNA synthesis of both inducible (HSPA1B) and constitutive (HSPA8) forms of HSP70 did increase in neutrophils between $0.5 \mathrm{~h}$ and $3 \mathrm{~h}$ after heat treatment for the $43^{\circ} \mathrm{C}$ regimen. A rise of mRNA synthesis was not seen with the $40^{\circ} \mathrm{C}$ regimen (Figure $3 \mathrm{~b}, \mathrm{c})$. No increase in HSP70 intracellular content was detected at later time points (more than $4.5 \mathrm{~h}$ incubation) after neutrophil treatment under either condition (Figure $3 d$ ). A considerable decrease in neutrophil numbers in the cell cultures after $15 \mathrm{~h}$ incubation connected with neutrophil apoptosis did not allow us to collect the data for appropriate statistics of HSP70 levels at the later time points.

Significant differences in HSP70 intracellular level dynamics were found for two heat treatment regimes used in this study. A biphasic pattern of HSP70 dynamics was observed during first hour after hyperthermia when neutrophils were treated at $43^{\circ} \mathrm{C}$ for $10 \mathrm{~min}$ (hereinafter designated as heat shock); no such pattern of the reaction was observed with the cell treatment at $40^{\circ} \mathrm{C}$ for $40 \mathrm{~min}$
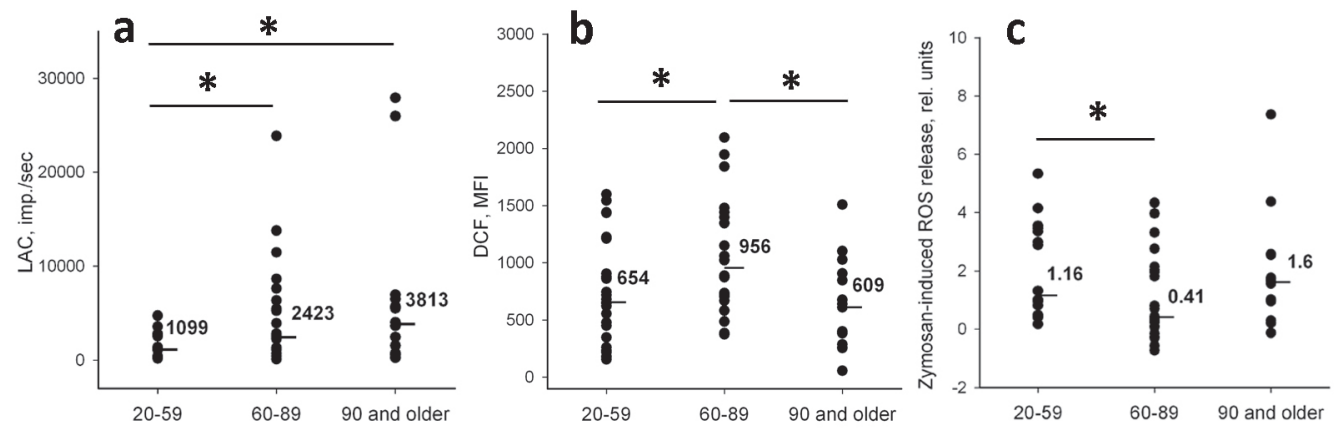

Figure 1: Relative levels of ROS generation in neutrophils isolated from donors of different age. (a) Spontaneous ROS production registered by LAC method $\left(\mathrm{ROS}_{\mathrm{LAC} \text { spont }}\right.$ ). (b) Spontaneous intracellular ROS generation registered with DCF probe (ROS spont $)$; mean fluorescence intensities (MFI) are presented. (c) ROS production stimulated with opsonized zymosan (ROS ${ }_{\text {LAC ind }}$ ). Line bars and numeric values are medians calculated for each group. Significance established at $\mathrm{p}<0.05$ is shown by asterisk. 


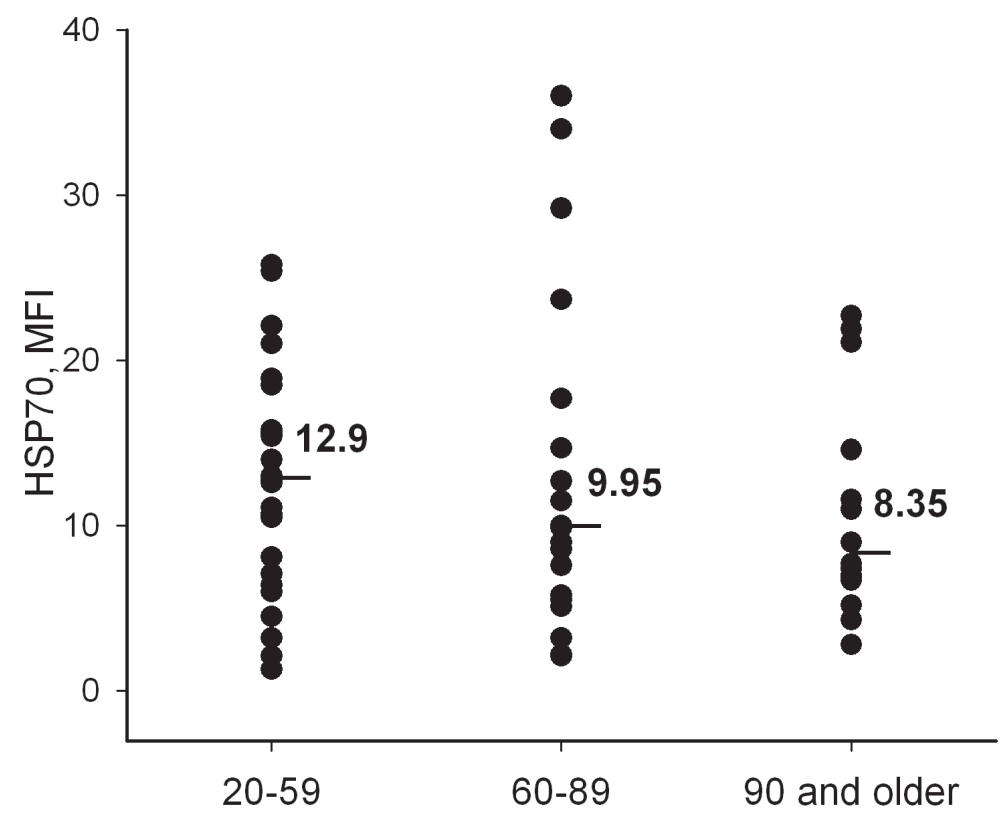

Figure 2: Intracellular content of HSP70 (HSP70 ${ }_{\text {basal }}$ ) measured in neutrophils by flow cytometry with anti-HSP70 antibody BRM-22 in different age groups. Line bars and numeric values present medians calculated for each group.

a

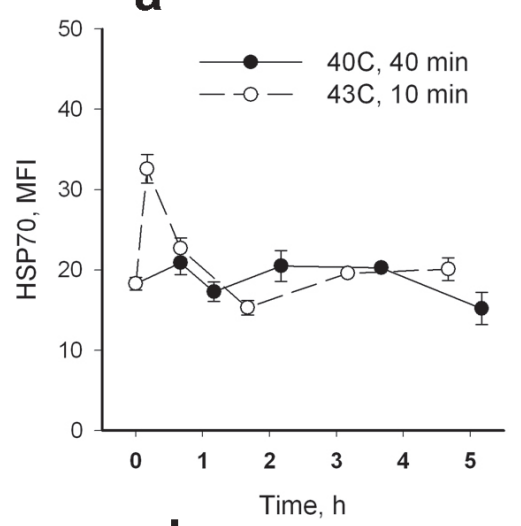

d

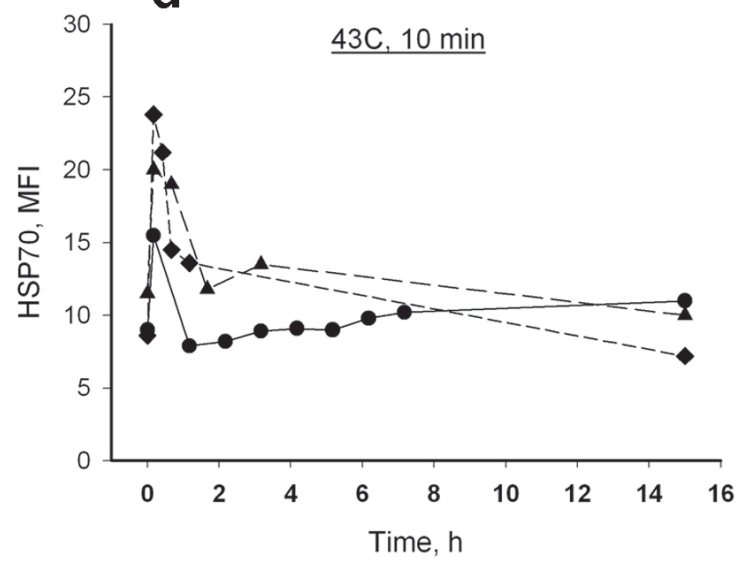

b

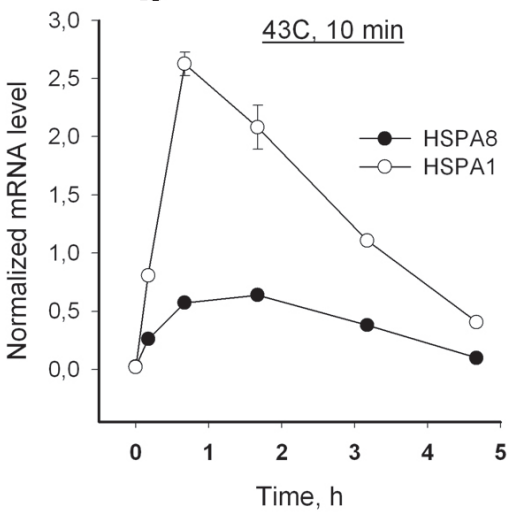

C

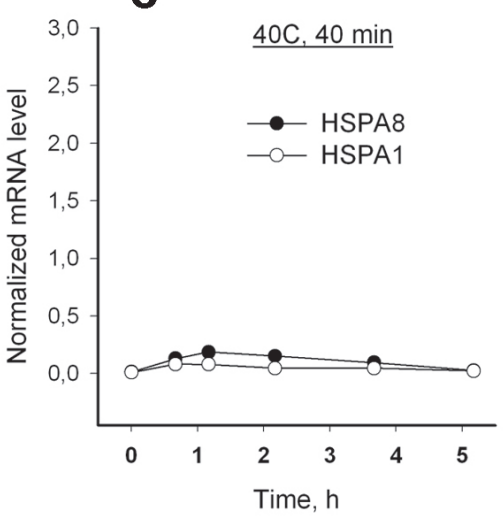

Figure 3: Dynamics of HSP70 response to hyperthermia in human neutrophils. (a) Intracellular HSP70 levels following heat treatment; $1-40^{\circ} \mathrm{C}, 40 \mathrm{~min} ; 2-43^{\circ} \mathrm{C}, 10 \mathrm{~min}$. (b, c) Induction of HSPAI and HSPA 8 mRNA synthesis in neutrophils by heat treatment at $40^{\circ} \mathrm{C}, 40 \mathrm{~min}(\mathrm{~b})$ and $43^{\circ} \mathrm{C}, 10 \mathrm{~min}(\mathrm{c})$; mRNA levels were normalized by b-actin. Data presented in A, B and C are the results of the same experiment with neutrophils isolated from a 22 year old donor. (d) Kinetics of intracellular level of HSP70 detected for $15 \mathrm{~h}$ in response to heat shock at $43^{\circ} \mathrm{C}, 10 \mathrm{~min}$, obtained in experiments with neutrophils from three donors. 
(Figure 3a). An increase of intracellular HSP70 levels was detected immediately after the heat shock termination; then a decrease of the HSP70 levels was observed within next 15-30 $\mathrm{min}$ (the typical dynamics curves are presented in Figure 4a).

We next focused on the two-phase pattern of intracellular HSP70 expression connected with immediate effect of heat shock on HSP70 levels as measured by flow cytometry. Two groups of monoclonal antibodies to HSP70 were used (three types of antibodies in each) displaying specificity to $N$ - or $C$-domain of HSP70 [31]. Surprisingly we did not detect any increase of HSP70 level after heat shock using antibodies to the $N$-end part of HSP70 responsible for binding with nucleotides. In contrast, antibodies recognizing the $C$-end substratebinding domain of HSP70 (SBD) showed an increase in HSP70 levels (Figure 4b, c). These results suggested that elevation of HSP70 intracellular level immediately after heat shock was mediated by increased availability of the protein epitopes for interaction with antibodies, rather than an increase of the total protein concentration in the cell. It is important to note that pre-incubation of neutrophils with protein synthesis inhibitor cycloheximide (100 $\mu \mathrm{M}, 30 \mathrm{~min}$ ) did not change the pattern of heat shock dependent intracellular HSP70 dynamics (data not shown) indicating that the observed rapid increase in HSP70 level was not associated with the synthesis of the proteins de novo, but may have been due to changes of the molecule conformation. We hypothesize that the conformational changes resulted in the increase of HSP70 level observed immediately after heat shock was connected with the exposure of antibody-binding epitopes of SBD due to dissociation of substrate molecules from HSP70 under the heat shock conditions. From this point of view the observed HSP70 increase after heat shock may indirectly show the amount of HSP70 engaged in functional interactions with client proteins before heat shock.

Next we examined and compared heat shockinduced elevation of intracellular HSP70 levels in different age groups. Like basal levels (HSP70 ${ }_{\text {basal }}$ ), the HSP70 levels measured immediately after heat shock $\left(\mathrm{HSP} 70_{\mathrm{HS}}\right)$ did not differ significantly between young, elder and nonagenarian donors (Figure 5a). However, the difference between $\mathrm{HSP} 7 \mathrm{HS}_{\mathrm{HS}}$ and $\mathrm{HSP} 70_{\text {basal }}\left(\Delta \mathrm{HSP} 70_{\mathrm{HS}}\right)$ for each person were shown to be significantly increased with age (Figure 5b).

\section{Correlation analysis of HSP70 and ROS parameters in neutrophils of different age groups}

Heat shock proteins are engaged in cell protection from damaging ROS action by preventing accumulation of denaturated proteins. The next task of the work was to study relationships between ROS production and intracellular HSP70 levels in neutrophils by correlation analysis. Taking into consideration that most of parameters analyzed in the study were shown to be age-dependent, we compared the relationships in young, elderly and nonagenarian age groups. Several values for both ROS production $\left(\operatorname{ROS}_{\text {LAC spont, }} \operatorname{ROS}_{\text {DCF spont, }} \operatorname{ROS}_{\text {LAC ind }}\right)$ and intracellular HSP70 (HSP70 ${ }_{\text {basal }}, \mathrm{HSP} 70_{\mathrm{HS}}$ and $\triangle \mathrm{HSP} 70_{\mathrm{HS}}$ ) were analyzed (Table 1).

Several significant correlations between the ROS and HSP70 parameters were revealed in all age groups suggesting that regulatory relationships might exist between intracellular HSP70 and ROS production in human neutrophils. However it seems unlikely that the relationships are direct, as they do not remain constant
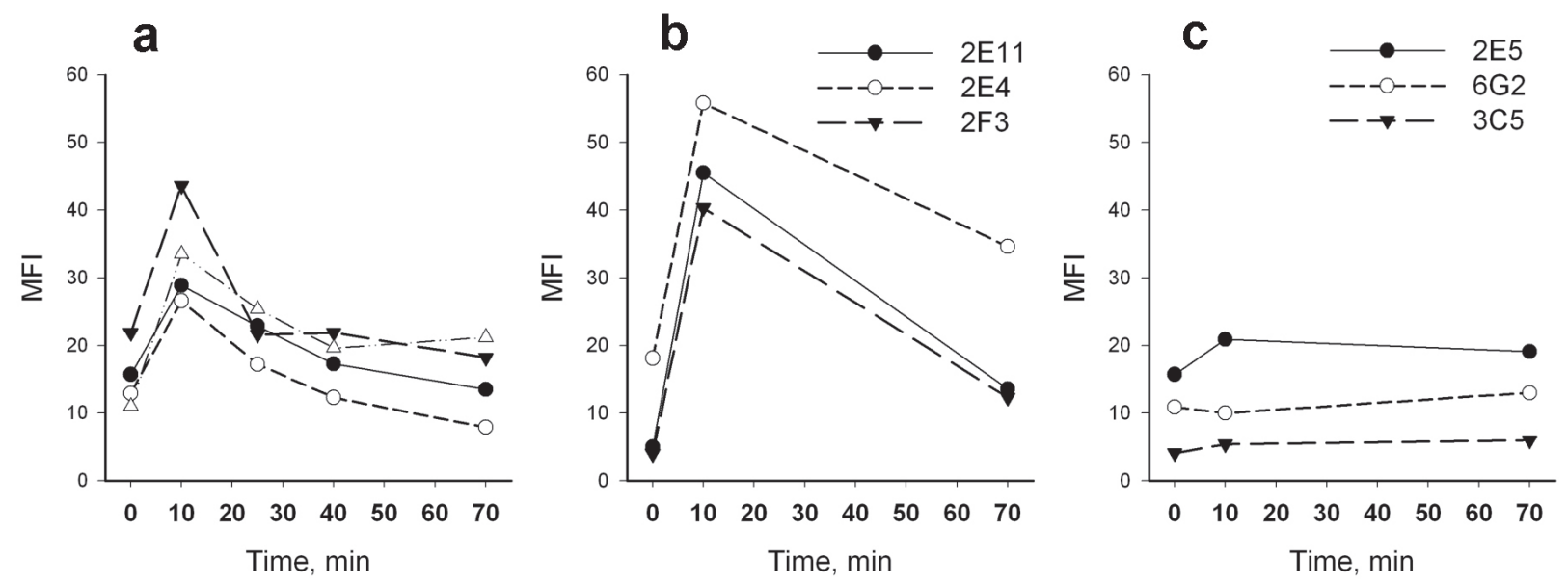

Figure 4: Dynamics of intracellular level of HSP70 after heat shock $\left(43^{\circ} \mathrm{C}, 10 \mathrm{~min}\right)$ analyzed by flow cytometry using different HSP70-specific antibodies (indicated in legend). (a) HSP70 dynamics measured with anti-HSP70 antibody BRM22 (4 donors of ages from 25 to 91 years). (b) HSP70 dynamics recorded with antibodies interacting with $C$-terminal domain of HSP70. (c) HSP70 dynamics recorded with antibodies interacting with $N$-terminal domain of HSP70. 
with age. Moreover, in different age groups both negative and positive correlations between HSP70 and ROS were found.

In the group of young donors $\mathrm{HSP} \mathrm{0}_{\text {basal }}$ was negatively correlated with $\operatorname{ROS}_{\text {LAC spont }}$ (Table 1) indicating an association of the lowest spontaneous LACdetected extracellular ROS production with the highest intracellular HSP70 content in neutrophils. Since there was no correlation between $\operatorname{ROS}_{\mathrm{LAC} \text { spont }}$ and $\triangle \mathrm{HSP} 70_{\mathrm{HS}}$ in this group, this negative correlation was not connected with "hidden" HSP70 portion displayed after heat shock. This probably indicated the level of HSP70 engaged in functional interaction with intracellular client proteins. This relationship disappeared with age; we did not found any correlation between $\mathrm{HSP} 0_{\text {basal }}$ and $\mathrm{ROS}_{\mathrm{LAC} \text { spont }}$ in older donor groups.

One of striking characteristics of HSP70-ROS relationships was revealed in the group of elders. Strong positive correlations were found between $\operatorname{ROS}_{\text {LAC ind }}$ and all parameters of intracellular HSP70 analyzed in this study (Table 1). Thus, in this age group high HSP70 content in neutrophils is associated with high ROS production induced by opsonized zymosan, considered as a protective immune response. So, in the age group between 60 and 89 years, when stimulated ROS production in neutrophils is significantly declined, increased expression of HSP70 can promote adequate ROS response of these cells to a pathogen, probably thanks to chaperone properties of the protein. Importantly, in the group of nonagenarians in which zymosan-induced ROS production was not changed comparing with the young group, no significant correlations between $\operatorname{ROS}_{\mathrm{LAC} \text { ind }}$ and HSP70 parameters were found, similar to the group of young donors.

The relationship in which $\Delta \mathrm{HSP} \mathrm{H}_{\mathrm{HS}}$ levels were negatively correlated with parameters of spontaneous ROS generation (registered by both DCF and LAC) was found only in the group of nonagenarians. Presumably, the accumulation of HSP70 interacting with their substrates in neutrophils is functionally associated with decreased spontaneous ROS production in this age group. No significant correlation was revealed for $\Delta \mathrm{HSP} 70_{\mathrm{HS}}$ with any ROS production parameters in the young donor group.

Thus, based on the correlation analysis carried out in our study several age-dependent types of relationships between intracellular HSP70 and ROS production in neutrophils can be suggested. However, mechanisms underlying the revealed HSP70-ROS parameter associations need to be further investigated.

\section{DISCUSSION}

Neutrophils use ROS for the destruction of pathogens. Intensive ROS production accompanies many processes in neutrophils including phagocytosis, response to pro-inflammatory stimuli and NET formation [32, 33]. In spite of diverse roles in cell signal cascades and gene expression, ROS also exert deleterious effects in the cells because of the oxidative modification of biological molecules. An intrinsic feature of neutrophils is a multilevel system of protection directed at elimination of ROS excess and reduction of harmful consequences of damaging ROS action. Intracellular HSP70 participates in this system by chaperon activity. Age-associated increase
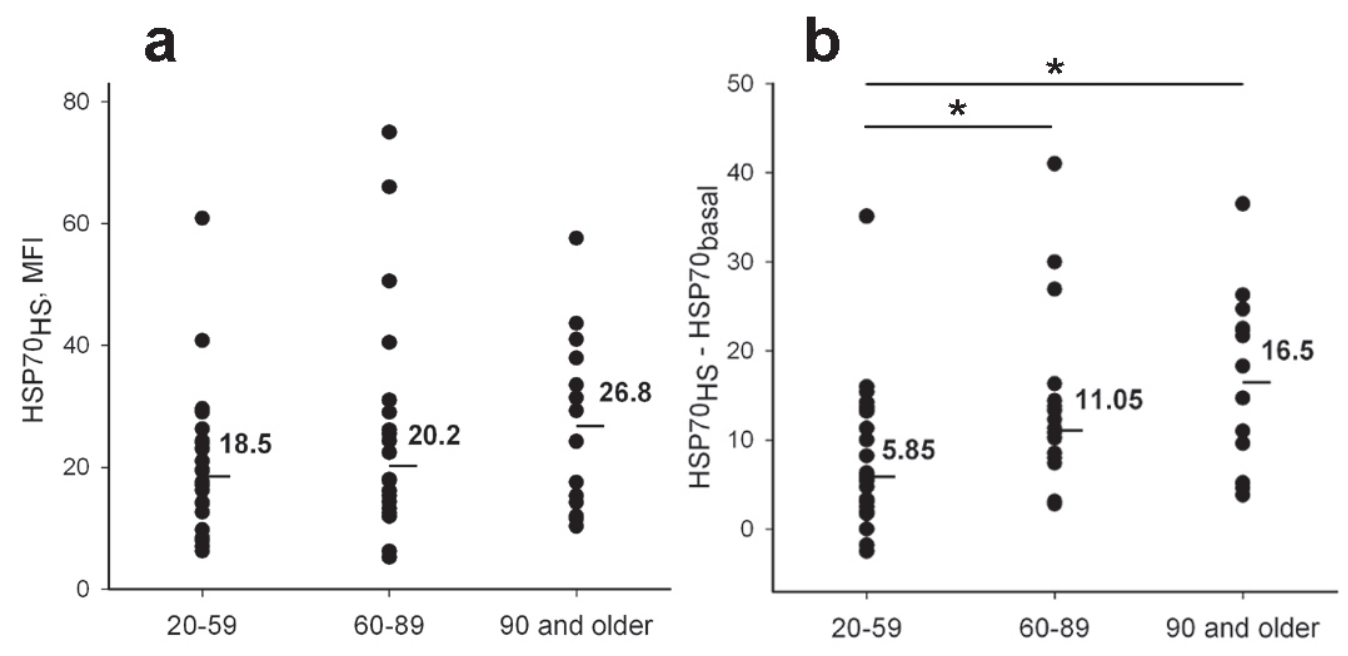

Figure 5: Comparison of heat shock induced elevation of intracellular HSP70 levels in neutrophils from different age groups. (a) HSP70 levels recorded immediately after heat shock (HSP70 ${ }_{\mathrm{HS}}$ ) (b) HSP70 level increase $\left(\Delta \mathrm{HSP} 70_{\mathrm{HS}}\right)$ calculated by subtraction of $\mathrm{HSP} 0_{\text {basal }}$ from $\mathrm{HSP} 70_{\mathrm{HS}}$. Line bars and numeric values present medians calculated for each group. Asterisks indicate significant difference between the groups $(\mathrm{p}<0.05)$. 
Table1: Correlation analysis of intracellular HSP70 and ROS production in neutrophils in different age groups $(\mathrm{r}$ - correlation coefficient, $\mathrm{p}-$ significance value $)$.

\begin{tabular}{|c|c|c|c|c|}
\hline Parameter 1 & Young donors & Elders & Nonagenarians & Parameter 2 \\
\hline \multirow{3}{*}{ HSP70 basal } & $\mathrm{r}=-0.086, \mathrm{p}=0.698$ & $\mathrm{r}=-0.063, \mathrm{p}=0.834$ & $\mathrm{r}=-0.319, \mathrm{p}=0.258$ & $\mathrm{ROS}_{\mathrm{DCF} \text { spont }}$ \\
\hline & $\begin{array}{l}\text { Negative } \\
r=-0.634, p=0.014\end{array}$ & $\mathrm{r}=0.082, \mathrm{p}=0.778$ & $r=0.273, p=0.377$ & $\mathrm{ROS}_{\mathrm{LAC}}$ spont \\
\hline & $\mathrm{r}=0.220, \mathrm{p}=0.435$ & $\begin{array}{l}\text { Positive } \\
r=0.615, p=0.024\end{array}$ & $\mathrm{r}=-0.329, \mathrm{p}=0.284$ & $\operatorname{ROS}_{\mathrm{LAC} \text { ind }}$ \\
\hline \multirow{3}{*}{$\mathrm{HSP} 70_{\mathrm{HS}}$} & $\mathrm{r}=-0.033, \mathrm{p}=0.880$ & $\mathrm{r}=-0.203, \mathrm{p}=0.513$ & $\begin{array}{l}\text { Negative } \\
r=-0.61, p=0.020\end{array}$ & ROS $_{\text {DCF spont }}$ \\
\hline & $\begin{array}{l}\text { Negative } \\
r=-0.719, p=0.003\end{array}$ & $r=0.297, p=0.313$ & $\mathbf{r}=-0.182, p=0.557$ & $\operatorname{ROS}_{\text {LAC spont }}$ \\
\hline & $r=-0.073, p=0.797$ & $\begin{array}{l}\text { Positive } \\
r=0.692, p=0.008\end{array}$ & $\mathrm{r}=-0.070, \mathrm{p}=0.817$ & $\mathrm{ROS}_{\mathrm{LAC} \text { ind }}$ \\
\hline \multirow{3}{*}{$\Delta \mathrm{HSP} 70_{\mathrm{HS}}$} & $\mathrm{r}=0.029, \mathrm{p}=0.896$ & $\mathrm{r}=-0.217, \mathrm{p}=0.484$ & $\begin{array}{l}\text { Negative } \\
r=-0.626, p=0.016\end{array}$ & $\mathrm{ROS}_{\mathrm{DCF} \text { spont }}$ \\
\hline & $\mathrm{r}=-0.007, \mathrm{p}=0.976$ & $\mathrm{r}=0.396, \mathrm{p}=0.173$ & $\begin{array}{l}\text { Negative } \\
r=-0.671, p=0.015\end{array}$ & $\mathrm{ROS}_{\mathrm{LAC} \text { spont }}$ \\
\hline & $\mathrm{r}=-0.420, \mathrm{p}=0.129$ & $\begin{array}{l}\text { Positive } \\
\mathrm{r}=0.560, \mathrm{p}=0.044\end{array}$ & $r=0.301, p=0.329$ & $\mathrm{ROS}_{\mathrm{LAC} \text { ind }}$ \\
\hline
\end{tabular}

of ROS generation and decline of anti-inflammatory, antioxidant or repairing systems may lead to elevation of amount of misfolded and aggregated proteins and a loss of this protective activity [34]. These phenomena are widely considered as the main causes of aging. From another point of view, over-stimulated signaling pathways related to cell growth and nutrient sensing, particularly mammalian target of rapamycin (mTOR)-associated pathways, and interplay of these pathways with ROS may lead to aging [35].

The present study confirms that ROS generation in neutrophils is dependent on age. Neutrophils in elderly donors had less effective functional ROS response to a stimulus whereas their spontaneous ROS production increased with age (Figure 1). In general, these results concur with published data on age-dependence of ROS production in neutrophils $[16,17]$. The delayed kinetics and decreased magnitude of ROS response in neutrophils was described earlier in elders $[9,36]$. High levels of spontaneous ROS production detected by LAC in elders and nonagenarians described in this work (Figure 1a) could be interpreted as such delayed response of neutrophils to 
previous stimuli. Increased spontaneous ROS generation can contribute to the low-grade inflammatory condition, or "inflamm-aging" status, reported for aged volunteers [18]. On the other hand, the high spontaneous ROS levels observed in nonagenarians do not correspond to the suggestion that increased ROS generation is the reason for life shortening.

Interestingly, correlation analysis demonstrated a discrepancy between spontaneous ROS generation levels registered by DCF or LAC $\left(\operatorname{ROS}_{\mathrm{DCF} \text { spont }}\right.$ and $\mathrm{ROS}_{\mathrm{LAC}}$ spont, respectively). Apparently, the main contribution to the $\operatorname{ROS}_{\text {LAC spont }}$ is connected with NADPH-oxidasemediated extracellular ROS production associated with the process of neutrophil activation. The level of intracellular ROS production measured by flow cytometry $\left(\operatorname{ROS}_{\text {DCF spont }}\right)$ may be connected with activity of other sources of ROS independent of NADPH-oxidase, in particular with oxidative phosphorylation in mitochondria. Respectively, ROS generation from distinct sources could be regulated differently. The absence of any correlation between $\operatorname{ROS}_{\mathrm{DCF} \text { spont }}$ and $\mathrm{ROS}_{\mathrm{LAC} \text { spont }}$ argues for this interpretation. At the same time, different forms of ROS might be detected by cytometric and chemiluminescence methods. Since fluorescence of DCF-DA is assumed to be proportional to the concentration of hydrogen peroxide in cells [37], various types of ROS including superoxide anion production may be measured non-specifically by luminol-dependent chemiluminescence [38].

We have shown that $\operatorname{ROS}_{\mathrm{DCF}}$ spont levels in nonagenarians, in contrast to $\operatorname{ROS}_{\mathrm{LAC} \text { spont }}$ levels, were similar to the levels in young group and significanly lower than in elders (Figure 1b). So, age-dependent elevation of extracellular ROS production does not imply a mandatory increase in intracellular ROS in neutrophils. The difference in $\mathrm{ROS}_{\mathrm{DCF} \text { spont }}$ levels between elders and nonagenarians might indicate that "antioxidant shield" is compromised in the elder group but remains undisturbed in nonagenarians where intracellular ROS are scavenged better. Another possibility is that some stress-mediated or activating intracellular events in neutrophils of elders resulted in excessive ROS generation. In its turn, the increase in intracellular ROS levels may lead to activation of ROS-dependent signaling pathways in neutrophils.

Excess of ROS may lead to intracellular molecular impairments in conditions with failed cell protection systems, in particular with deficit of protective heat shock proteins. We have analyzed possible age dependence of intracellular content of HSP70 in neutrophils. Flow cytometric analysis of intracellular HSP70 in intact neutrophils did not reveal any significant difference between the three age groups of donors (Figure 2). For further analysis we used a model with heat treatment of neutrophils in vitro. It is known that heat shock evokes two types of effects on the cells. Direct effects involve conformational changes of proteins, changes in interactions between proteins and alterations in activity of proteins as a result of various chemical modifications. Secondary effects become apparent as activation of certain signaling pathways and induction of heat shock protein expression for subsequent protection of cells. However in neutrophils we could not detect a pronounced induction of HSP70 protein accumulation by heating the cells at $40^{\circ} \mathrm{C}$ or at $43^{\circ} \mathrm{C}$, despite an observed increase in gene expression at the second higher temperature (Figure 3 ). It is interesting that mRNA of both inducible and constitutive forms of HSP70 increased after the treatment. It is possible that the mechanism of protection involving accumulation of HSP70 following heat shock is not easily detectable in such short-lived cell population as neutrophils. Nevertheless, this does not exclude a protective role of HSP70 permanently expressed in neutrophils, particularly taking into account that these cells actively produce ROS and should be well armed against oxidative stress.

Using a series of monoclonal antibodies against HSP70 we next demonstrated the differences in heat shock induced dynamics of intracellular HSP70 levels detected with antibodies recognizing either the $\mathrm{N}$-terminal part or the C-terminal part of HSP70 molecule (Figure 4). A heat shock associated increase in intracellular HSP70 levels measured with antibodies specific to the C-terminal part of HSP70 containing the substrate-binding domain was not connected with HSP70 synthesis de novo but was related to conformational changes in the HSP70 molecule. This was due to an increase in availability of the SBD structure for interactions with the antibodies. Detailed information about conformational alterations in HSP70 molecule associated with the change of a client protein was published recently [39, 40]. Presumably, the difference between initial and heat shock induced intracellular HSP70 levels $\left(\Delta \mathrm{HSP} 70_{\mathrm{HS}}\right)$ was related to the numbers of HSP70 molecules involved in active interaction with substrates and released from the molecular complexes upon the cell heating. Importantly, this is the only parameter between HSP70 parameters studied in this work that demonstrated dependence on age (Figure 5). $\Delta \mathrm{HSP} \mathrm{H}_{\mathrm{HS}}$ was found to increase in both elders and nonagenarians. It is known that aging is associated with increasing concentration of aggregated and mis-folded proteins [41]. All these proteins need HSP70 assistance in cells. Possibly $\triangle \mathrm{HSP}_{\mathrm{HS}}$ level indirectly determines the amount of the impaired proteins interacting with HSP70 in neutrophils. Cell stress might result in a replacement of the target proteins. From this point of view, the increased $\triangle \mathrm{HSP} 7 \mathrm{O}_{\mathrm{HS}}$ in aged individuals argues for effective HSP70-mediated cell protection in old age.

The main focus of this work was to determine if there was any close relationship between ROS generation and intracellular HSP70 expression in neutrophils. To address this question we performed correlation analysis of HSP70 and ROS parameters. A number of the correlations (both positive and negative) have been found (Table) which implies that such relationships might exist. Some 
other findings support this suggestion. It was shown earlier that HSP70-mediated heat tolerance prevented inhibition of NADPH oxidase and superoxide dismutase activity caused by heat shock in phagocytes [42]. Spontaneous ROS production by neutrophils was demonstrated to be negatively associated with HSP70 in plasma [17]. However, until now there is no clear mechanism proposed for these relationships.

The correlations between intracellular HSP70 and ROS production we observed in neutrophils showed significant age-dependent differences (Table). Importantly, none of the relationships in groups of old donors (elders and nonagenarians) were similar to the correlations found in the group of young people evidenced an essential effect of aging on the relationships analyzed in our work.

In young donors, the low spontaneous extracellular ROS production $\left(\operatorname{ROS}_{\text {LAC spont }}\right)$, which can be interpreted as a normal state in resting neutrophils, was associated with high level of intracellular HSP70 (Table). Mechanistically, this can be explained in two ways: 1) intracellular level of HSP70 decreases following an increase of ROS generation; 2) initial low HSP70 level provokes somehow an elevation of $\operatorname{ROS}_{\text {LAC spont }}$ which we attribute to NADPHoxidase-mediated ROS production. Although our data favor neither hypothesis, some arguments can be made in support of the first one. In spite of the fact that HSP70 can contribute to late stage anti-oxidant protection, these proteins also might be subjected to the destructive action of ROS. HSP70s have been shown to stabilize the lysosome membrane [43]. ROS-mediated carbonylation of HSP70 with subsequent cleavage by calpain was suggested as a mechanism of lysosomal rupture associated with oxidative stress [44]. Other possibility is that stressinduced release of HSP70 associated with the lysosomal compartment mediates the decrease of intracellular HSP70 [45]. However it is not clear whether these processes occur in neutrophils. It should be noted that in nonagenarians spontaneous ROS production was negatively correlated with $\triangle \mathrm{HSP} 70_{\mathrm{HS}}$ levels, itself age-dependent. The biological significance of this association needs further studies.

It is noticeable that elders were the only age group where positive correlations, notably correlations between HSP70 levels (HSP70 ${ }_{\text {basal }}, \mathrm{HSP}_{\mathrm{HS}}$ and $\Delta \mathrm{HSP} 70_{\mathrm{HS}}$ ) and zymosan-induced ROS production, were found. Obviously, sufficient amounts of intracellular HSP70 preserved the ROS response of neutrophils to pathogens that was decreased in general within the elders. This suggests an important role for HSP70 in the maintenance of adequate reaction of neutrophils to danger stimuli.

Of particular interest to this study is previous studies demonstrating that characteristics of neutrophils of very old donors (over 80-90 years old) including chemotaxis, phagocytosis, expression of adhesion molecules, intracellular ROS levels, apoptosis rate and antioxidant activities show less difference with young people than with slightly younger old donors in the 60-70-years old range [46-48]. These observations have led to the conclusion that long lived individuals can be considered as a model of successful aging [49]. In this work we found several important differences between elderly volunteers and nonagenarians. Some of characteristics measured in the nonagenarian group were more similar to the young donor group than to the elders. Particularly, levels of zymosan-induced $\mathrm{ROS}_{\mathrm{LAC} \text { ind }}$ produced in neutrophils of elderly people were lower than in the groups of both nonagenarians and young volunteers (Figure 1c). This suggests that neutrophil-associated immune defense may function better in nonagenarians in comparison with the elderly. The highest intracellular spontaneous ROS production in neutrophils was revealed in the group of elders suggesting that these cells are at the risk of oxidative stress. No positive correlation between HPS70 and induced ROS response levels was found in nonagenarians in contrast to elders. Basing on the successful aging model we assume that the noticed set of characteristics specific only for elders do not relate to longevity.

Discrepancies in the correlations found in elders and nonagenarians indicated different mechanisms of HSP70-ROS interplay in these age groups supporting that the relationship was not direct. The dissimilarity of patterns of ROS-HSP70 association and ROS levels in neutrophils for different age groups may be explained basing on hyperfunction theory of aging. In this concept, unintentional continuation of developmental growth of a mature organism is accepted as the main factor causing aging. On the cell level, mechanism of aging is connected with growth signaling, in particular through mTORcentric pathways, leading to the cell over-stimulation, i.e. hyperfunction [4, 50]. Chronic inflammation mediated largely by activated neutrophils may be considered as a typical example of hyperfunction on the organismal level [5]. Neutrophils actively use mTOR pathway for regulation of inflammatory cytokine production, NET formation and ROS generation [51-53]. On the other hand, ROS were shown to be involved in mTOR pathway regulation and outcome [54]. This ROS interplay with mTOR-centered signaling pathways may promote aging $[55,56]$. We can speculate that mTOR pathway is overstimulated in neutrophils in most of elders, in contrast to young people and nonagenarians, resulting in or being accompanied by the increase of intracellular ROS generation in these cells. This overstimulation condition may lead to decreased responsiveness of neutrophils to recurrent activating stimuli because of development of compensatory resistance to the signals that can be a reason for declined ROS response of neutrophils to opsonized zymosan in elder group. We can also suggest that at the stage of signal-resistance the cells use all their reserves to maintain normal cell functioning in the presence of high amount of intracellular ROS. Heat shock proteins executing chaperone functions play in these conditions a role directed to protection of cell signal pathways that can 
support zymosan-induced ROS response in neutrophils. This may explain the registered in our study positive correlation between the level of zymosan-induced ROS production and all analyzed parameters of intracellular HSP70 in neutrophils of elders (Table).

The absence of the positive HSP70-ROS correlations in neutrophils of nonagenarians may be considered as a factor associated with longer life span of people in this group, along with higher intracellular content of HSP70 associated with more protective ROS response, an important immune function of neutrophils. Conversely, the positive association between intracellular HSP70 and zymosan-induced ROS production could anticipate individuals at a higher risk of mortality prior to their 90th year.

\section{MATERIALS AND METHODS}

\section{Participants}

26 healthy young persons (aged 20-59, 13 men, median 30.5), 24 elders (aged 60-89, 9 men, median 73.5) and 15 nonagenarians (aged 90 and over, 7 men, median 91) registered as patients of the Moscow Clinical Centre of Gerontology were recruited to the study. Inclusion criteria for the participation were the absence of active pathologies (history of acute infection, tumor, apoplexy, myocardial infarction), treatment with corticosteroids or high doses of nonsteroid anti-inflammatory drugs for all subjects and the independent living for elders and nonagenarians. The study has been approved by the local research ethics committee. All participants gave their informed consent prior to the study.

\section{Neutrophil isolation}

Neutrophils were isolated from peripheral blood within $2 \mathrm{~h}$ after blood sampling by centrifugation at $500 \mathrm{~g}$ for $30 \mathrm{~min}$ at RT in density gradient using PolymorphPrep separation medium (Axis-Shield, Sweden). Fractions containing neutrophils were then collected. Cells were washed twice (400 g, $15 \mathrm{~min}$ ) in Dulbecco's phosphate buffer saline (DPBS), resuspended in RPMI-1640 media (Sigma-Aldrich, USA) supplemented with $2 \mathrm{mM}$ $L$-glutamine, $15 \mathrm{mM}$ HEPES and 2\% fetal calf serum (HyClone, Thermo Scientific, USA) (referred hereafter to as assay media) at concentration of $2 \times 10^{6}$ cells $/ \mathrm{ml}$ and left for $30 \mathrm{~min}$ prior to use in assays. Routinely, neutrophil purity was assessed by flow cytometry analysis and was routinely found to be $\geq 95 \%$. Cell viability determined by trypan blue staining was no less than $97 \%$.

\section{Measurement of spontaneous intracellular ROS production}

Spontaneous intracellular ROS generation $\left(\mathrm{ROS}_{\mathrm{DCF} \text { spont }}\right)$ in neutrophils was determined using 2'-7'-dichlorodihydrofluorescein diacetate (DCFHDA, Invitrogen, USA) [37]. The probe was added to neutrophils resuspended in assay media $(500 \mu \mathrm{l})$ at $5 \mu \mathrm{g} /$ $\mathrm{ml}$ final concentration. After incubation for $20 \mathrm{~min}$ at $37^{\circ} \mathrm{C}$ cells were washed twice with DPBS at $4^{\circ} \mathrm{C}$. Fluorescence at $530 \mathrm{~nm}$ was then measured in neutrophils by flow cytometry on BD FACSCalibur flow cytometer (San Jose, CA) with excitation at $488 \mathrm{~nm}$.

\section{ROS measurement by luminol-amplified chemiluminometry}

ROS production was assessed by luminol-amplified chemiluminometric method [30]. Neutrophils $\left(2 \times 10^{5}\right.$ cells/ sample) were stimulated with zymosan A (Sigma-Aldrich, USA) opsonized with a freshly prepared serum pool of 10 donors at a final concentration of $20 \mathrm{mg} / \mathrm{ml}$ to induce ROS production. The reaction was carried out at $37^{\circ} \mathrm{C}$ in plastic tubes in colorless Hank's Balanced Salt Solution (HBSS) $(200 \mu \mathrm{l})$ and $1 \mu \mathrm{M}$ luminol (Serva, Germany) in a volume $400 \mu \mathrm{l}$. The level of chemiluminescence in the cell samples was measured by using 3603 chemiluminometer (Dialog Joint Venture, Russia). Numbers of light pulses per minute $(\mathrm{cpm})$ were registered. The kinetics of the level of chemiluminescence was recorded for $30 \mathrm{~min}$. Spontaneous ROS production was measured before zymosan treatment as initial count per minute (cpm) level. For calculation of zymosan-induced ROS production in a sample the maximal cpm level was used. Experiments were performed in duplicate.

\section{Heat treatment and intracellular HSP70 immunolabeling}

Neutrophils in assay media were dispensed into polypropylene tubes $\left(10^{6}\right.$ cells in $\left.500 \mu \mathrm{l}\right)$ and heated in a constant-temperature water bath at $40^{\circ} \mathrm{C}$ for $40 \mathrm{~min}$ or at $43^{\circ} \mathrm{C}$ for $10 \mathrm{~min}$ (heat shock). Some of the samples after heat treatment were then incubated at $37^{\circ} \mathrm{C}$ for different time intervals. Intracellular levels of HSP70 were then determined by indirect immunofluorescent staining followed by flow cytometry analysis. For intracellular labeling the neutrophils were fixed and permeabilized in DPBS containing 2\% paraformaldehyde (Riedel-de Haen, Germany), 0.05\% BSA and 0.05\% Triton X-100 (SigmaAldrich, USA) at $37^{\circ} \mathrm{C}$ for $15 \mathrm{~min}$. The permeabilized neutrophils were treated in $100 \mu \mathrm{l}$ volume with primary HSP70-specific monoclonal antibody BRM22 (SigmaAldrich, USA) or in HSP70-specific B-hybridoma 
supernatants in 1:100 dilutions for $30 \mathrm{~min}$ at RT and then stained with secondary sheep anti-mouse IgG Fabfragments conjugated with PE (Sigma-Aldrich, USA) for $30 \mathrm{~min}$ at RT. Each stage of labeling was followed by two washes with DPBS containing $0.2 \%$ BSA and $0.1 \%$ Triton $\mathrm{X}-100$. The cells were finally resuspended in DPBS and analyzed by flow cytometry. HSP70 intracellular levels were determined as means of fluorescence intensity (MFI) corrected for background fluorescence of the negative controls.

\section{Flow cytometry}

Flow cytometry analysis was carried out on a FACSCalibur flow cytometer (BD Biosciences, USA) equipped with 488 and $640 \mathrm{~nm}$ lasers and an appropriate set of detectors and filters. Neutrophils were identified and gated using forward and side light scatter. A minimum of 10000 gated events was collected for each sample. Data were analyzed using CellQuest ver. 3.4 (BD Biosciences) and FlowJo version 7.6.5 flow cytometry analysis programs.

\section{Real-time PCR}

Total RNA for each time point was extracted from 6×106 neutrophils using TRIzol reagent (MRC, UK). All RNA samples were treated with DNaseI (Thermo Scientific, USA) to remove residual DNA. Total RNA was quantified with NanoVue Plus spectrophotometer at A260/A280 (GE Healthcare Life Science, UK). cDNA synthesis was performed using random hexamer primers with addition of MINT Reverse Transcriptase (Evrogen, Russia) following the manufacturer's instructions. The hexamer primers (12 pmole) were annealed in $10 \mu \mathrm{l}$ of a mixture containing $2 \mu \mathrm{g}$ total RNA. The mixture was heated for $2 \mathrm{~min}$ at $70^{\circ} \mathrm{C}$ and then chilled on ice for 10 min. To synthesize cDNA, the reaction mixtures were incubated at $42^{\circ} \mathrm{C}$ and for $70^{\circ} \mathrm{C}$ for $120 \mathrm{~min}$ and $15 \mathrm{~min}$, respectively. Real-time PCR primers (5'-3') designed with Primer Blast software (www.ncbi.nlm.nih.gov/tools/ primer-blast) and controlled with OligoAnalyzer 3.1 program are listed below (gene: forward primer, reverse primer).

HSPA1: AGGTGCAGGTGAGCTACAAG, CTCGGCGATCTCCTTCATC;

HSPA8: TGCTGCTCTTGGATGTCACT,
AAGGTCTGTGTCTGCTTGGT;

b-actin: CACCACACCTTCTACAATGAG, GTCTCAAACATGATCTGGGTC.

The specific fragments were amplified and then checked by $3 \%$ agarose gel electrophoresis to detect a single product of the expected size.

\section{Real-time PCR detection}

Each real-time PCR mixture (final volume $25 \mu \mathrm{l}$ ) contained $5 \mu$ of qPCRmix-HS SYBR mixture (Evrogen, Russia), $1 \mu \mathrm{l}$ of $3 \mathrm{mM}$ forward and reverse primers, 0.5 $\mu \mathrm{l}$ of cDNA template, and $17.5 \mu \mathrm{l}$ of nuclease-free water. The reactions were carried out using a LightCycler 480 Real-time PCR detection system (Roche Diagnostics, Deutschland $\mathrm{GmbH}$ ) as follows: pre-incubation at $95^{\circ} \mathrm{C}$ (5'), and then 40 cycles of $95{ }^{\circ} \mathrm{C}$ for $10 \mathrm{~s}, 60^{\circ} \mathrm{C}$ for 10 $\mathrm{s}$, and $72{ }^{\circ} \mathrm{C}$ for $10 \mathrm{~s}$. At the end of the amplification, a dissociation curve was plotted to confirm the specificity of the product. All real-time experiments were repeated in triplicates. The gene expression ratio was estimated as the difference in quantity from samples that treated under the heating $43^{\circ} \mathrm{C} 10 \mathrm{~min}$ versus $40^{\circ} \mathrm{C} 40 \mathrm{~min}$. The results were normalized against house-keeping gene b-actin to correct the sample-to-sample variation.

\section{Statistical analysis}

Statistical analysis was performed using SigmaPlot ver. 11.0 (Systat Software Inc.). For data that followed a normal distribution t-tests were performed to estimate differences between two groups. For non-normally distributed data a Mann-Whitney $U$ test was used. Correlation analysis was done using Spearman rank order method. Results were considered statistically significant at $\mathrm{p} \leq 0.05$.

\section{ACKNOWLEDGMENTS}

This work was partly supported by the Russian Foundation for Basic Research (grant \# 14-04-01280) and by the Program "Nanotechnologies \& Nanomaterials" of the Russian Academy of Sciences. Authors declare no conflict of interests.

\section{REFERENCES}

1. Harman D. Ageing: a theory based on free radical and radiation chemistry. J Gerontol. 1956; 11:298-300.

2. Saunders LR and Verdin E. Cell biology. Stress response and aging. Science. 2009; 323:1021-1022.

3. Höhn A, König J and Grune T. Protein oxidation in aging and the removal of oxidized proteins. J Proteomics. 2013; 92:132-159.

4. Blagosklonny MV. Answering the ultimate question "what is the proximal cause of aging?". Aging (Albany NY). 2012; 4(12):861-877.

5. Franceschi C, Bonafè M, Valensin S, Olivieri F, De Luca $\mathrm{M}$, Ottaviani E and De Benedictis G. Inflamm-aging. An evolutionary perspective on immunosenescence. Ann N Y Acad Sci. 2000; 908:244-254. 
6. Caielli S, Banchereau J and Pascua V. Neutrophils come of age in chronic inflammation. Curr Opin Immunol. 2012; 24:671-677.

7. Halliwell B. Free radicals, reactive oxygen species and human disease: a critical evaluation with special reference to atherosclerosis. Br J Exp Pathol. 1989; 70:737-757.

8. Jaillon S, Galdiero MR, Del Prete D, Cassatella MA, Garlanda C and Mantovani A. Neutrophils in innate and adaptive immunity. Semin Immunopathol. 2013; 35(4):377394.

9. Fulop T, Larbi A, Douziech N, Fortin C, Guérard KP, Lesur O, Khalil A and Dupuis G. Signal transduction and functional changes in neutrophils with aging. Aging Cell. 2004; 3(4):217-226.

10. Butcher SK, Chahal H, Nayak L, Sinclair A, Henriquez NV, Sapey E, O'Mahony D and Lord JM. Senescence in innate immune responses: reduced neutrophil phagocytic capacity and CD16 expression in elderly humans. J Leukoc Biol. 2001; 70(6):881-886.

11. Hazeldine J, Harris P, Chapple IL, Grant M, Greenwood H, Livesey A, Sapey E and Lord JM. Impaired neutrophil extracellular trap formation: a novel defect in the innate immune system of aged individuals. Aging Cell. 2014; 13(4):690-698.

12. Fulop T, Fouquet C, Allaire P, Perrin N, Lacombe G, Stankova J, Rola-Pleszczynski M, Gagné D, Wagner JR, Khalil A and Dupuis G. Changes in apoptosis of human polymorphonuclear granulocytes with aging. Mech Ageing Dev. 1997; 96:15-34.

13. Oishi K and Machida K. Inhibition of neutrophil apoptosis by antioxidants in culture medium. Scand J Immunol. 1997; 45(1):21-27.

14. Tortorella C, Simone O, Piazzolla G, Stella I, Cappiello $\mathrm{V}$ and Antonaci S. Role of phosphoinositide 3-kinase and extracellular signal-regulated kinase pathways in granulocyte macrophage-colony-stimulating factor failure to delay fas-induced neutrophil apoptosis in elderly humans. J Gerontol A Biol Sci Med Sci. 2006; 61(11):1111-1118.

15. Solana R, Tarazona R, Gayoso I, Lesur O, Dupuis G and Fulop T. Innate immunosenescence: effect of aging on cells and receptors of the innate immune system in humans. Semin Immunol. 2012; 24(5):331-341.

16. Fortin CF, McDonald PP, Lesur O and Fülöp T Jr. Aging and neutrophils: there is still much to do. Rejuvenation Res. 2008; 11(5):873-882.

17. Ogawa K, Suzuki K, Okutsu M, Yamazaki K and Shinkai $\mathrm{S}$. The association of elevated reactive oxygen species levels from neutrophils with low-grade inflammation in the elderly. Immun Ageing. 2008; 24:5:13.

18. Peters T, Weiss JM, Sindrilaru A, Wang H, Oreshkova T, Wlaschek M, Maity P, Reimann J and ScharffetterKochanek K. Reactive oxygen intermediate-induced pathomechanisms contribute to immunosenescence, chronic inflammation and autoimmunity. Mech Ageing Dev. 2009;
130(9):564-587.

19. Bernadett K and Greensmith L. Induction of heat shock proteins for protection against oxidative stress. Advanced Drug Delivery Reviews. 2009; 61:310-318.

20. Niforou K, Cheimonidou C and Trougakos IP. Molecular chaperones and proteostasis regulation during redox imbalance. Redox Biol. 2014; 30(2):323-332.

21. Saibil H. Chaperone machines for protein folding, unfolding and disaggregation.Nat Rev Mol Cell Biol. 2013; 14(10):630-642.

22. Jaattela M. Heat shock proteins as cellular lifeguards. Ann. Med. 1999; 31:261-271.

23. Murshid A, Eguchi T and Calderwood SK. Stress proteins in aging and life span. Int J Hyperthermia. 2013; 29(5):442447.

24. Njemini R, Lambert M, Demanet C, Kooijman R and Mets $\mathrm{T}$. Basal and infection-induced levels of heat shock proteins in human aging. Biogerontology. 2007; 8(3):353-364.

25. Calderwood SK, Murshid A and Prince T. The shock of aging: molecular chaperones and the heat shock response in longevity and aging. Gerontology. 2009; 55(5):550-558.

26. Rea IM, McNerlan S and Pockley AG. Serum heat shock protein and anti-heat shock protein antibody levels in aging. Exp Gerontol. 2001; 36(2):341-352.

27. Njemini R, Bautmans I, Onyema OO, Van Puyvelde K, Demanet $\mathrm{C}$ and Mets T. Circulating heat shock protein 70 in health, aging and disease. BMC Immunol. 2011; 28:1224.

28. Salway KD, Gallagher EJ, Page MM and Stuart JA. Higher levels of heat shock proteins in longer-lived mammals and birds. Mech Ageing Dev. 2011; 132(6-7):287-297.

29. Terry DF, Wyszynski DF, Nolan VG, Atzmon G, Schoenhofen EA, Pennington JY, Andersen SL, Wilcox MA, Farrer LA, Barzilai N, Baldwin CT and Asea A. Serum heat shock protein 70 level as a biomarker of exceptional longevity. Mech Ageing Dev. 2006; 127:862-868.

30. Allen RC and Loose LD. Phagocytic activation of a luminol-dependent chemiluminescence in rabbit alveolar and peritoneal macrophages. Biochem Biophis Res Commun. 1976; 69:245-52.

31. Boyko AA, Vetchinin SS, Sapozhnikov AM and Kovalenko EI. Alterations in heat shock protein $70 \mathrm{kDa}$ levels in human neutrophils under the heat shock conditions. Bioorg Khim. 2014; 40(5):528-540.

32. Segal AW. How neutrophils kill microbes. Annu. Rev. Immunol. 2005; 23:197-223.

33. Brinkmann V, Reichard U, Goosmann C, Fauler B, Uhlemann Y, Weiss DS, Weinrauch Y and Zychlinsky A. Neutrophil Extracellular Traps Kill Bacteria. Science. 2004; 303 (5663):1532-1535.

34. Squier TC. Oxidative stress and protein aggregation during biological aging. Exp Gerontol. 2001; 36(9):1539-1550.

35. Blagosklonny MV. Aging: ROS or TOR. Cell Cycle. 2008; 
7(21):3344-54.

36. Klut ME, Ruehlmann DO, Li L, Whalen BA, Van Breemen $\mathrm{C}$ and Hogg JC. Age-related changes in the calcium homeostasis of adherent neutrophils. Exp. Gerontol. 2002; 37:533-541.

37. Bass DA, Parce JW, Dechatelet LR, Szejda P, Seeds $\mathrm{MC}$ and Thomas M. Flow cytometric studies of oxidative product formation by neutrophils: a graded response to membrane stimulation. J Immunol. 1983; 130(4):19101917.

38. Vladimirov YA and Proskurnina EV. Free radicals and cell chemiluminescence. Biochemistry (Mosc). 2009; 74(13):1545-1566.

39. Zhuravleva A, Clerico EM and Gierasch LM. An interdomain energetic tug-of-war creates the allosterically active state in Hsp70 molecular chaperones. Cell. 2012; 151(6):1296-1307.

40. Kityk R, Kopp J, Sinning I and Mayer MP. Structure and dynamics of the ATP-bound open conformation of Hsp70 chaperones. Mol Cell. 2012; 48(6):863-874.

41. Cuanalo-Contreras K, Mukherjee A and Soto C. Role of protein misfolding and proteostasis deficiency in protein misfolding diseases and aging. Int J Cell Biol. 2013; 2013:638083.

42. Polla BS, Stubbe H, Kantengwa S, Maridoneau-Parini I and Jacquier-Sarlin MR. Differential induction of stress proteins and functional effects of heat shock in human phagocytes. Inflammtion. 1995; 19(3):363-378.

43. Agarraberes FA and Dice JF. A molecular chaperone complex at the lysosomal membrane is required for protein translocation. J Cell Sci. 2001; 114:2491-2499.

44. Yamashima T. Reconsider Alzheimer's disease by the 'calpain-cathepsin hypothesis'-a perspective review. Prog Neurobiol. 2013; 105:1-23.

45. Mambula SS and Calderwood SK. Heat shock protein 70 is secreted from tumor cells by a nonclassical pathway involving lysosomal endosomes. J Immunol. 2006; 177:849-857.

46. Niwa Y, Kasama T, Miyachi Y and Kanoh T. Neutrophil chemotaxis, phagocytosis and parameters of reactive oxygen species in human aging: cross-sectional and longitudinal studies. Life Sci. 1989; 44(22):1655-1664.

47. Moroni F, Di Paolo ML, Rigo A, Cipriano C, Giacconi R, Recchioni R, Marcheselli F, Malavolta M and Mocchegiani E. Interrelationship among neutrophil efficiency, inflammation, antioxidant activity and zinc pool in very old age. Biogerontology. 2005; 6:271-281.

48. Alonso-Fernández P, Puerto M, Maté I, Ribera JM and de la Fuente M. Neutrophils of centenarians show function levels similar to those of young adults. J Am Geriatr Soc. 2008; 56(12):2244-2251.

49. Cevenini E, Invidia L, Lescai F, Salvioli S, Tieri P, Castellani $\mathrm{G}$ and Franceschi C. Human models of aging and longevity. Expert Opin Biol Ther. 2008; 8(9):1393-1405.
50. Blagosklonny MV. Cell cycle arrest is not yet senescence, which is not just cell cycle arrest: terminology for TORdriven aging. Aging (Albany NY). 2012; 4(3):159-165.

51. Lindemann SW, Yost CC, Denis MM, McIntyre TM, Weyrich AS and Zimmerman GA. Neutrophils alter the inflammatory milieu by signal-dependent translation of constitutive messenger RNAs. Proc Natl Acad Sci U S A. 2004; 101(18):7076-7081.

52. Itakura A and McCarty OJ. Pivotal role for the mTOR pathway in the formation of neutrophil extracellular traps via regulation of autophagy. Am J Physiol Cell Physiol. 2013; 305(3):C348-354.

53. Rolas L, Makhezer N, Hadjoudj S, El-Benna J, Djerdjouri $\mathrm{B}$, Elkrief L, Moreau R and Périanin A. Inhibition of mammalian target of rapamycin aggravates the respiratory burst defect of neutrophils from decompensated patients with cirrhosis. Hepatology. 2013; 57(3):1163-1171.

54. Radisavljevic ZM and Gonzalez-Flecha B. TOR kinase and Ran are downstream from PI3K/ Akt in H2O2-induced mitosis. J Cell Biochem. 2004; 91:1293-1300.

55. Halicka HD, Zhao H, Li J, Lee YS, Hsieh TC, Wu JM and Darzynkiewicz Z. Potential anti-aging agents suppress the level of constitutive mTOR- and DNA damage- signaling. Aging (Albany NY). 2012; 4(12):952-965.

56. Pani G. P66SHC and ageing: ROS and TOR? Aging (Albany NY). 2010; 2(8):514-518. 